\title{
Some Remarks on Antenna Response in a Reverberation Chamber
}

\author{
L. K. Warne and K.S.H.Lee
}

Abstract - The simple formula, $\left\langle\mathrm{P}_{\mathrm{r}}\right\rangle=\left(\mathrm{E}_{\mathrm{o}}^{2} / \eta\right)\left(\lambda^{2} / 8 \pi\right)$, for the received power of an
antenna with a matched load in an over-moded cavity actually holds for an
antenna of any shape and size. This can be seen from the close connection
between the correlation tensor of the cavity field at two different points and the
imaginary part of the free-space dyadic Green's function.

Index Terms - Antenna response, reverberation chamber, correlation tensor, dyadic Green's function.

L. K. Warne is with Sandia National Laboratories, Albuquerque, New Maxico

K.S.H. Lee is with ITT Industries, Los Angeles, CA 


\section{DISCLAIMER}

This report was prepared as an account of work sponsored by an agency of the United States Government. Neither the United States Government nor any agency thereof, nor any of their employees, make any warranty, express or implied, or assumes any legal liability or responsibility for the accuracy, completeness, or usefulness of any information, apparatus, product, or process disclosed, or represents that its use would not infringe privately owned rights. Reference herein to any specific commercial product, process, or service by trade name, trademark, manufacturer, or otherwise does not necessarily constitute or imply its endorsement, recommendation, or favoring by the United States Government or any agency thereof. The views and opinions of authors expressed herein do not necessarily state or reflect those of the United States Government or any agency thereof. 


\section{DISCLAIMER}

Portions of this document may be illegible in electronic image products. Images are produced from the best available original document. 
In a recent article [1], Hill has showed that the statistical average of the received power of a linear dipole with a matched load and a special form of current distribution is given by

$$
\left\langle\mathrm{P}_{\mathrm{r}}\right\rangle=\frac{\mathrm{E}_{0}^{2}}{\eta} \frac{\lambda^{2}}{8 \pi}
$$

First, we will show that (1) is valid for a linear antenna with any current distribution. To do this we notice that the correlation function $\rho_{z}\left(z_{1}, z_{2}\right)$ given by (18) in [1] can be expressed as

$$
\rho_{\mathrm{z}}\left(\mathrm{z}_{1}, \mathrm{z}_{2}\right)=\frac{3}{2 \mathrm{k}}\left(1+\frac{1}{\mathrm{k}^{2}} \frac{\partial^{2}}{\partial \mathrm{z}_{1}^{2}}\right) \frac{\sin \left[\mathrm{k}\left(\mathrm{z}_{1}-\mathrm{z}_{2}\right)\right]}{\mathrm{z}_{1}-\mathrm{z}_{2}}=\frac{6 \pi}{\mathrm{k}} \operatorname{Im} \Gamma_{\mathrm{zz}}
$$

where $\operatorname{Im} \Gamma_{z z}$ is the imaginary part of the zz-component of the free-space dyadic Green's function $\Gamma[2]$,

$$
\Gamma\left(\overrightarrow{\mathrm{r}}_{1}, \overrightarrow{\mathrm{r}}_{2}\right)=\frac{1}{4 \pi}\left(\mathbf{u}+\frac{1}{\mathrm{k}^{2}} \nabla_{1} \nabla_{1}\right) \frac{\mathrm{e}^{\mathrm{ikr}}}{\mathrm{r}}
$$

along the z-axis, with $r=\left|\vec{r}_{1}-\vec{r}_{2}\right|, \mathbf{u}=$ unit dyad. One can show that (2) is indeed true by simply carrying out the differentiation, as is done in [2]. Now the power radiated, $\mathrm{P}_{\text {rad }}$, by a linear antenna with current distribution $\mathrm{I}(\mathrm{z})$ is given by

$$
\begin{aligned}
P_{\text {rad }} & =\frac{\omega \mu}{2} \iint \vec{J}\left(\vec{r}_{1}\right) \cdot \operatorname{Im} \Gamma \cdot \vec{J}^{*}\left(\vec{r}_{2}\right) d V_{1} d V_{2} \\
& =\frac{\omega \mu}{2} \iint I\left(z_{1}\right)\left[\operatorname{Im} \Gamma_{z z}\left(z_{1}-z_{2}\right)\right] I^{*}\left(z_{2}\right) d z_{1} d z_{2} \\
& \equiv \frac{1}{2} R_{d}\left|I_{o}\right|^{2}
\end{aligned}
$$


Hence the double integration in (22) of [1] has the value

$$
\iint \rho_{\mathrm{z}}\left(\mathrm{z}_{1}, \mathrm{z}_{2}\right) \mathrm{I}\left(\mathrm{z}_{1}\right) \mathrm{I}^{*}\left(\mathrm{z}_{2}\right) \mathrm{dz_{1 }} d \mathrm{z}_{2}=\frac{3 \lambda^{2}}{2 \pi \eta} \mathrm{R}_{\mathrm{d}}\left|\mathrm{I}_{\mathrm{o}}\right|^{2}
$$

where we have made use of (2) and (4). Substitution of (5) in (22) of [1] gives formula (1) for any current distribution on a linear antenna.

Next, we will show that formula (1) also holds for a matched antenna of any shape and size. To prove this we have to work out the statistical average of the correlation dyad of the electric field at two different points in the cavity, i.e., $\left\langle\overrightarrow{\mathrm{E}}\left(\overrightarrow{\mathrm{r}}_{1}\right) \overrightarrow{\mathrm{E}}^{*}\left(\overrightarrow{\mathrm{r}}_{2}\right)\right\rangle$. We define

$$
R_{i j}=\frac{1}{2}\left[\left\langle E_{i}\left(\vec{r}_{1}\right) E_{j}^{*}\left(\vec{r}_{2}\right)\right\rangle+\left\langle E_{i}^{*}\left(\vec{r}_{1}\right) E_{j}\left(\vec{r}_{2}\right)\right\rangle\right] \quad i, j=x, y, z
$$

In view of (2) one should not be surprised to find that

$$
\mathrm{R}_{\mathrm{ij}}=\frac{6 \pi}{\mathrm{k}} \operatorname{Im} \Gamma_{\mathrm{ij}}
$$

To verify (7) we first carry out all the necessary differentiations in (3) and obtain

$$
\begin{aligned}
\frac{4 \pi}{\mathrm{k}} \operatorname{Im} \Gamma_{\mathrm{ij}} & =\left[3 \frac{\sin \mathrm{u}}{\mathrm{u}^{5}}-3 \frac{\cos \mathrm{u}}{\mathrm{u}^{4}}-\frac{\sin \mathrm{u}}{\mathrm{u}^{3}}\right] \mathrm{u}_{\mathrm{i}} \mathrm{u}_{\mathrm{j}} \\
& +\left[\frac{\sin \mathrm{u}}{\mathrm{u}}+\frac{\cos \mathrm{u}}{\mathrm{u}^{2}}-\frac{\sin \mathrm{u}}{\mathrm{u}^{3}}\right] \delta_{\mathrm{ij}}
\end{aligned}
$$

where $\mathrm{u}=\mathrm{kr}, \mathrm{u}_{\mathrm{x}}=\mathrm{k}\left(\mathrm{x}_{1}-\mathrm{x}_{2}\right), \mathrm{u}_{\mathrm{y}}=\mathrm{k}\left(\mathrm{y}_{1}-\mathrm{y}_{2}\right)$, etc., and $\delta_{\mathrm{ij}}$ is the Kronecker delta. To work out the left-hand side of (7) we invoke what has been known in isotropic homogeneous turbulence, which enables one to write [3] 


$$
R_{i j}=-\frac{1}{2 r} f^{\prime} r_{i} r_{j}+\left(f+r f^{\prime} / 2\right) \delta_{i j}
$$

where $r_{x}=x_{1}-x_{2}$, etc. and $f^{\prime}=d f / d r$. The scalar function $f$ can be identified with $\rho_{z}\left(z_{1}, z_{2}\right)$ in [1] and is often referred to as the longitudinal correlation function given by

$$
f(r)=\frac{3}{k^{2} r^{2}}\left(\frac{\sin k r}{k r}-\cos k r\right)=\frac{3}{u^{2}}\left(\frac{\sin u}{u}-\cos u\right)
$$

Using (10) in (9) gives $3 / 2$ times the right-hand side of (8), and thus (7) is verified. Hence,

$$
\begin{aligned}
\left\langle\mathrm{P}_{\mathrm{r}}\right\rangle & =\frac{\mathrm{E}_{\mathrm{o}}^{2}}{12 \mathrm{R}_{\mathrm{d}}\left|\mathrm{I}_{\mathrm{o}}\right|^{2}} \iint \mathrm{J}_{\mathrm{i}}\left(\overrightarrow{\mathrm{r}}_{\mathrm{i}}\right) \mathrm{R}_{\mathrm{ij}}(\mathrm{r}) \mathrm{J}_{\mathrm{j}}^{*}\left(\overrightarrow{\mathrm{r}}_{2}\right) d V_{1} d V_{2} \\
& =\frac{E_{\mathrm{o}}^{2}}{\eta} \frac{\lambda^{2}}{8 \pi}
\end{aligned}
$$

where repeated indices are summed. Note that the trace of $R_{i j}$ is

$$
R_{x x}+R_{y y}+R_{z z}=3 \frac{\sin k r}{k r}
$$

Thus far we have proved that formula (1) is valid for a matched receiving antenna of any shape and size. The underlying assumption for (1) to hold is that the cavity is highly over-moded in the sense that many overlapping modes are present within the bandwidth of one resonant mode. It would be interesting to show how the simple formula (1) would be modified for a receiving antenna in an under-moded cavity where the frequency is still quite high but operates in a range where the spectra of the resonant modes are well separated.

Before concluding two remarks are in order. It is worthwhile to mention that formula (1) can also be obtained by averaging the effective receiving area $\mathrm{A}_{\mathrm{e}}$ over all angles of incidence and polarization of an incident plane wave in free space, i.e., 


$$
\left\langle\mathrm{P}_{\mathrm{r}}\right\rangle=\frac{\mathrm{E}_{0}^{2}}{\eta}\left\langle\mathrm{A}_{\mathrm{e}}\right\rangle=\frac{\mathrm{E}_{0}^{2}}{\eta}\left\langle\frac{\lambda^{2}}{4 \pi} \mathrm{Gpq}\right\rangle=\frac{\mathrm{E}_{0}^{2}}{\eta} \frac{\lambda^{2}}{8 \pi}
$$

since $\int \mathrm{Gd} \Omega / 4 \pi=1, \int \mathrm{pd} \chi / 2 \pi=1 / 2$ and $\mathrm{q}=1$ for a matched load, where $\mathrm{G}$ is the antenna's directivity gain and $\mathrm{p}$ the polarization mismatch factor [2]. The other point to be made is that there is a boundary layer near the cavity wall, which is about one wavelength thick (see Fig. 1 and [4]). It is not clear if formula (1) needs to be changed when part of the receiving antenna is immersed in the layer. 


\section{REFERENCES}

[1] D. A. Hill, "Linear dipole response in a reverberation chamber," IEEE Trans. Electromagn. Compat., vol.41, pp. 365-368, November 1999.

[2] C.H. Papas, Theory of Electromagnetic Wave Propagation, McGraw-Hill, New York, pp.34-35 and pp.142-143, 1965.

[3] G.K. Batchelor, The Theory of Homogeneous Turbulence, Cambridge University Press, pp. 40-50, 1960.

[4] John M. Dunn, "Local, high-frequency analysis of the fields in a mode-stirred chamber," IEEE Trans. Electromagn. Compat., vol. 32, pp. 53-58, February 1990. 


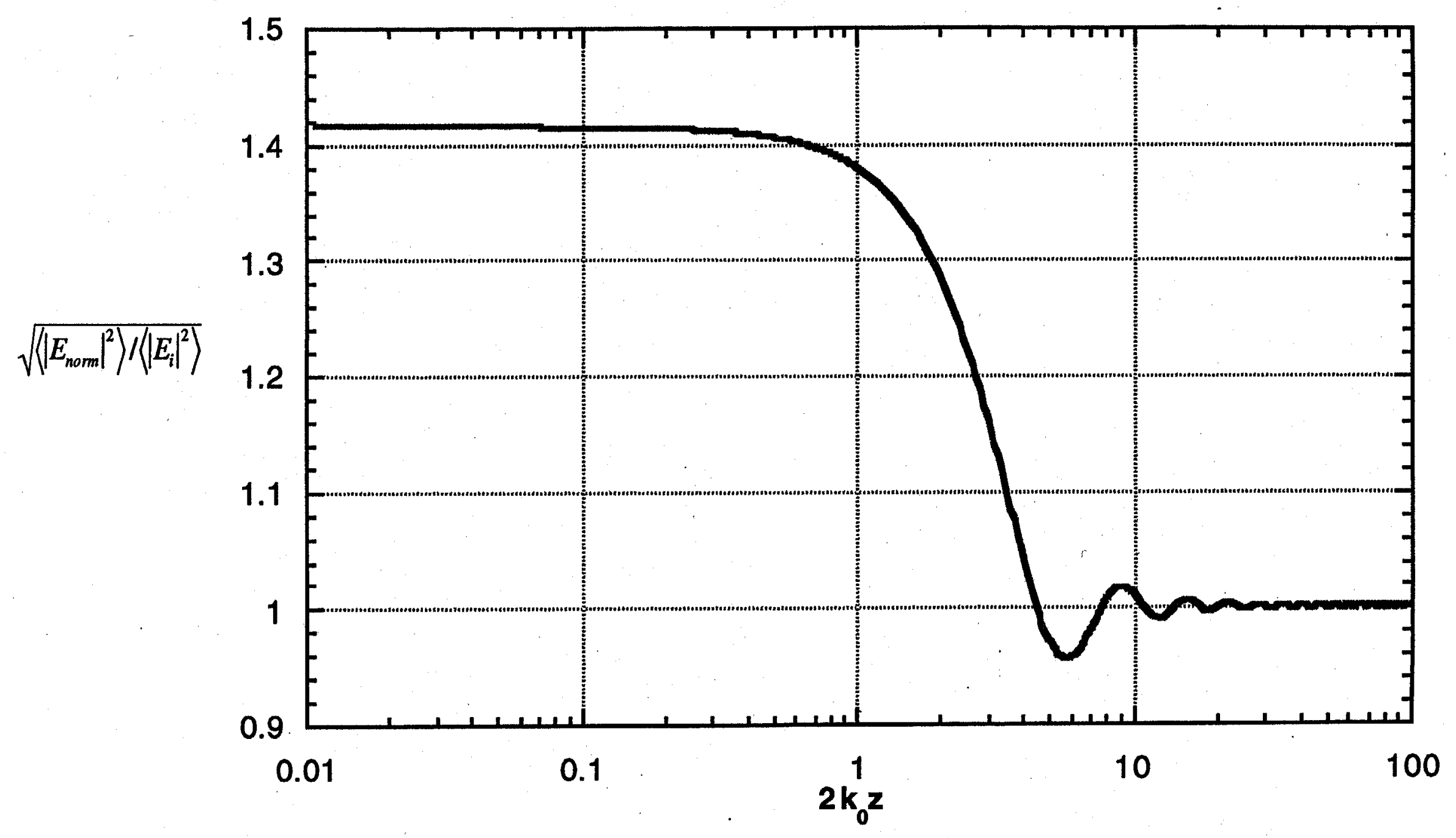

Figure 1. The transition region between cavity wall and isotropic homogeneous region. $\left\langle\left|E_{i}\right|^{2}\right\rangle=E_{0}^{2} / 3, i=x, y$, or $z$ 